\title{
Políticas territoriais, ciência \& tecnologia e a ação de atores locais e regionais. O Pólo de Modernização Tecnológica da Serra - Rio Grande do Sul - Brasil ${ }^{1}$
}

este artigo analisam-se ações estratégicas implementadas pelo Estado (poder público estadual e municipal) e por organizações da sociedade civil, representativas de comunidades locais e regionais (na escala regional-local) e no âmbito das políticas públicas de ciência e tecnologia no Rio Grande do Sul e de programas que contêm características de desenvolvimento endógeno. A análise de tais ações, circunstanciadas ao processo de reforma do Estado na via da descentralização político-administrativa e da relativa inserção da sociedade civil na gestão pública, implica o reconhecimento de uma nova escala de poderes - a regional-local. A sociedade civil, em sua forma de relativa participação, através dos Conselhos Regionais de Desenvolvimento (Coredes) - e entre 1999 e 2002, no governo da Frente Popular, no Orçamento Participativo Estadual -, tenderia a implantar novos usos políticos do território, na medida em que esses poderes regionais-locais têm passado a desenvolver alianças com o Estado e a construir projetos de futuro.

* Doutor em Ciências - Geografia Humana pela Universidade de São Paulo; membro do Programa de Pós-Graduação em Geografia/Análise Territorial da Universidade Federal do Rio Grande do Sul.

1 O artigo sintetiza comunicação realizada no Seminário Agricultura, Meio Ambiente e Sociedade no Programa de PósGraduação em Desenvolvimento Rural (PGDR) da UFRGS, janeiro de 2003. 


\section{Políticas territoriais}

A questão de investigação está circunstanciada à análise de políticas de ciência e tecnologia enquanto políticas territoriais, um dos núcleos da Geografia Política e Regional. As tendências recentes de análise, principalmente após a Constituição Federal de 1988, compõem-se de um leque abrangente e múltiplo de investigação localizado, por exemplo, nas relações entre Estado, mercado e sociedade civil (Becker, 1983, 1984, 1988, 1991, 1995; Costa, 1988).

No âmbito das tendências recentes, tem relevância o conceito de flexibilização do Estado em relação ao território (Becker, 1991, p 47-56), o que equivale a reconhecer a emergência de múltiplos poderes e novos usos políticos do território, que imprimem a estes novas formas. Estas podem ser apreendidas no sentido que Ihes atribui Santos (1985, p. 50-51), relacionadas a função, processo e estrutura. ${ }^{2}$ Os novos usos políticos do território estão associados ao sentido da flexibilização do Estado, na transição do Estado Desenvolvimentista para um Estado de corte comercial (Rosecrance, 1986). Essa flexibilização pode ser apreendida em três grandes vias da reforma do Estado: a) a descentralização político-administrativa; b) a inserção da sociedade civil na reforma política do Estado e c) a relação Estado-mercado.

A multidimensionalidade do poder (Raffestin, 1993; Becker, 1983, 1988) é conceituada no sentido de que diferentes atores produzem o espaço, (re)estruturam o território através da prática de poderes/políticas/programas estratégicos, gestão territorial, enfim, ações/programas que tenham um caráter (re)estruturante, de acordo com os paradigmas da competitividade, inserção (subordinada) internacional (Fiori,1995, p.VI) e

2 "Forma é o aspecto visível de uma coisa. Refere-se, ademais, ao arranjo ordenado de objetos, a um padrão. Tomada isoladamente, temos uma mera descrição de fenômenos ou de um de seus aspectos num dado instante do tempo. (...) A forma pode ser imperfeitamente definida como uma estrutura técnica ou objeto responsável pela execução de determinada função. As formas são governadas pelo presente e, conquanto se costume ignorar o seu passado, este continua a ser parte integrante das formas. Estas surgiram dotadas de certos contornos e finalidades-funções. Diante do exposto, torna-se evidente que a função está diretamente relacionada com sua forma, portanto, a função é a atividade elementar de que a forma se reveste." (Santos, 1985, p. 50-51). 
com capacidade de alavancagem de desenvolvimento endógeno, imprimindo, assim, novos usos do território. Interpretar o poder relacionado ao território significa relacioná-lo à capacidade dos atores de gerir, de implantar políticas econômicas e tecnológicas, com incidência estratégica no território, por parte tanto do Estado como dos múltiplos atores do/no poder, em alianças ou conflitos na gestão de políticas por capitais privados e por segmentos da sociedade civil que representam as diferentes regióes do território.

As estratégias de desenvolvimento regional/local projetadas por organizações civis respondem, no plano das regióes de planejamento no estado do Rio Grane do Sul, à questão geral que se tem tomado de Lefebvre, de que o espaço é um instrumento político e que sua representação está sempre a serviço de uma estratégia projetada (1976, p. 25; 31). Um Pólo de Modernização Tecnológica pode ser conceituado como uma forma com estrutura técnica com funções estratégicas para a economia e o território, no sentido de que os resultados de suas ações de inovação sejam perceptíveis em determinados raios de alcance local e regional (difusão) no âmbito do sistema produtivo.

\section{O desenvolvimento endógeno com base local}

À região, na escala regional-local, ou ao local, o vivido territorial (Raffestin, 1993) associa-se a questão do desenvolvimento endógeno com base local. A literatura sobre política pública, que tem documentado a decrescente influência do Estado-Nação, tem trazido a questão da iniciativa local no desenvolvimento econômico. As proposições de desenvolvimento endógeno (Wilson, 1995; Martin, 1996; Boisier, 1996a, 1997; Mattos, 1997; Braga, 1999; Boisier, 2000; Barquero, 2001) enfatizam os fatores que o território contém. Ao mesmo tempo em que reconhece sua incorporação em estruturas mais amplas, as proposições chamam a atenção para o território onde se dá o agrupamento das relações sociais, o lugar onde se en- 
contram as forças endógenas e exógenas. A nova literatura reconhece a necessária ação recíproca com as forças da globalização e a crescente natureza aberta da economia local (Guimarães, 1995; Boisier, 1996a; Ferrão, 1995, 1996; Antonelli; Ferrão, 2001).

Descentralização política e desenvolvimento local, aqui tomados enquanto marcos referenciais das ações examinadas no Pólo de Modernização Tecnológica da Serra, em Caxias do Sul, encontram-se associados. Boisier, Sabatini et al. (1994, p. 351-389) argumentam que a descentralização, particularmente a descentralização político-territorial, é uma condição necessária para a obtenção da transformação produtiva. As questões que se colocam à análise na escala local advêm, portanto, das políticas de desenvolvimento que contenham determinados recortes de caráter endógeno. Nesse sentido, a questão apontaria para uma busca de relações entre as ações dos atores político-territoriais - como sujeitos do desenvolvimento local - e políticas de inovação .

Nos modelos de crescimento endógeno (Mattos,1997, p.3), o tipo de regulação por parte do Estado é de ordem intermediária, orientado a gerar um ambiente favorável à inversão privada, de forma a estimular a acumulação endógena de capital físico e humano, a pesquisa e o desenvolvimento e aumento da capacidade e da competitividade empresariais. Os critérios para as políticas são, entre outros, a gestão das externalidades, a provisão de bens públicos, a regulação do setor financeiro e as relações econômicas externas, a eliminação das distorções econômicas e a manutenção de um marco legal da ordem pública.

No cenário contextual contemporâneo, o desenvolvimento endógeno e o desenvolvimento territorial estão associados à sociedade civil (Boisier, 1995). O conceito de desenvolvimento territorial (expressão ampla que inclui o desenvolvimento de microlocalidades, tais como comunas e regiões em escala intermediária entre o local e o estadual) refere-se agora a processos de mudanças socioeconômicas de caráter estrutural, delimitados geogra- 
ficamente e inseridos num marco configurado por sistemas econômicos de mercado, ampla abertura externa e descentralização dos sistemas de decisão.

\section{As escalas geográficas de poder}

A adoção das escalas geográficas de poder como recurso metodológico para a análise de ações regionais e locais é um método de procedimento essencial para a compreensão do sentido e da visibilidade dos fenômenos numa perspectiva espacial. A escala, como uma estratégia de representação e apreensão da realidade, define o campo empírico da pesquisa de investigação e de análise (Castro, 1995, p. 120), facilita o uso de construções teóricas e interpretações sobre as tendências contemporâneas das transformações territoriais.

O processo parcial de substituição das macrorregiões nacionais por regiões na escala regional-local - um nível de agregação das comunidades locais no interior do Estado-Nação (Becker, 1988, p. 109) - e a multiplicidade de organizações interessadas no fortalecimento da comunidade local põem em relevo as escalas regional-local e local stricto sensu. Tal processo pode corresponder, em termos de ações de desenvolvimento de corte endógeno, no Rio Grande do Sul, a algumas experiências de Conselhos de Desenvolvimento Regional e às ações de governos locais na perspectiva de apoio institucional à implantação de inovações tecnológicas nos territórios municipais. Os Conselhos, organizações comunitárias territoriais, instâncias autônomas de direito privado não-estatais, com procedimentos de coordenação horizontal e descentralizada, localizadas no eixo comunitário, encontramse no escopo do conjunto de espaços diferenciados de desenvolvimento.

Algumas das ações dos Conselhos, em cujas regiões estão implantados pólos de modernização tecnológica, tenderiam, hipoteticamente, a preparar as regiões tanto para os novos paradigmas produtivos para a competição, seja no mercado interno, seja no externo quanto para a agregação de 
valor às mercadorias e geração de emprego e renda. A ciência e a tecnologia, um dos componentes da construção da competitividade sistêmica como política de caráter nacional e estadual (Becerra, 1994; Coutinho; Ferraz, 1995), têm no Rio Grande do Sul, com a intermediação da escala regionallocal, a interiorização via Conselhos de Desenvolvimento Regional, a alocação dos pólos tecnológicos nas universidades regionais, federais e comunitárias de caráter fundacional e confessionais.

No âmbito das políticas de construção deliberada da competitividade, o papel da política de ciência e tecnologia e dos pólos tecnológicos, no plano do desenvolvimento local, assume relevância como um componente de uma estratégia de desenvolvimento territorial. Tal estratégia pode implicar a seletividade de centros urbanos de porte médio e mesmo pequenos, que contenham potencial do fator conhecimento, bem como em regiões contíguas, ou não, que passam a se articular política e economicamente com os fluxos de informação e de mercadorias.

\section{A escala regional-local: a região do Corede Serra}

A região, tomada como amostra de campo para evidenciar a ação dos atores regionais no processo de desenvolvimento endógeno com base local, é representativa da macrorrregião Nordeste, qual seja, a do ConseIho Regional de Desenvolvimento da Serra. A inserção progressiva dessa região na dinâmica nacional de crescimento industrial constitui uma característica básica que guarda, contudo, a importância de alguns gêneros industriais que ainda dependem da base agrária local, como a indústria vinícola, por exemplo. Entre a Região Metropolitana de Porto Alegre e a de Caxias do Sul, a área da encosta da Serra Geral compõe o eixo industrial que vem sendo referido como eixo metropolitano, à medida que seu conteúdo urbano-industrial está vinculado ao processo de crescimento de Porto Alegre. 
O Corede Serra, localizado na macrorregião Nordeste do estado, está contido no extremo meridional do novo polígono industrial do país (Diniz, 1994). Conforme Bandeira (1995, p. 232-233), no Rio Grande do Sul, verifica-se ao longo das últimas décadas uma desconcentração-concentrada do crescimento industrial, análoga à verificada no conjunto do país. A região Nordeste do Rio Grande do Sul, que inclui Porto Alegre e seu entorno, afirma o autor, aumentou sua participação no total estadual, de 55,06\% em 1959 para mais de $72 \%$ em 1988 . O crescimento do parque manufatureiro concentrou-se, portanto, em locais próximos da capital, principalmente em municípios situados na própria Região Metropolitana, ou ao longo do eixo Porto Alegre-Caxias do Sul.

\section{A escala local - os municípios de Caxias do Sul e Campestre da Serra}

A escala local de análise do desenvolvimento territorial relaciona-se às microlocalidades, os municípios, a menor unidade institucional político-administrativa. Estes, progressivamente, passam a assumir questões relativas à gestão territorial numa escala que, muitas vezes, transcende as fronteiras municipais, na qual diferentes atores passam, progressivamente, a implementar programas de desenvolvimento de caráter endógeno. Os lugares (municípios) tomados como amostra para evidenciar a ação dos atores locais em ações de desenvolvimento de corte endógeno são Caxias do Sul e Campestre da Serra, nos quais o poder público municipal tem atuado em aliança com a Universidade de Caxias do Sul, o Conselho Regional de Desenvolvimento da Serra e diversas organizações locais, em programas do Pólo de Modernização da Serra. 
As alianças estratégicas dos governos locais com organizações civis, em projetos reestruturantes ou inovadores, compõem o cenário da gestão do desenvolvimento local/regional. O Estado na escala local (o município) é um dos atores, mas não o menos importante, tendo em vista seu papel de ordenador jurídico-político-territorial e de representante das coletividades.

\section{A análise de programas e articulações regionais}

O exame de programas deu-se através do a) Programa do Pólos Tecnológicos (programa em escala estadual nas gestões dos governos estaduais nos períodos 1987-1991; 1992-1994;1995-1998); b) três programas do Pólo de Modernização Tecnológica da Serra e c) relações e articulações dos atores político-territoriais locais e/ou regionais na implementação de programas estratégicos (governos locais nas gestões municipais 1993-1996, principalmente, e estadual 1992-1994;1995-1998) e suas articulações com os atores privados no Pólo de Modernização Tecnológica da Serra.

As organizações representativas dos segmentos produtivos e organizações tomadas nesta variável são o Corede Serra, Universidade de Caxias do Sul, Câmara da Indústria, Comércio e Serviços de Caxias do Sul e prefeituras municipais de Caxias do Sul e de Campestre da Serra em programas do Pólo de Modernização Tecnológica da Serra.

Para a análise do tema examina-se na seqüência: a) o Programa dos Pólos Tecnológicos da Secretaria de Ciência e Tecnologia, b) o mapa organizacional do território na região em exame e c) programas do Pólo de Modernização Tecnológica da Serra, como o Pólo Oleoquímico de Plantas Aromáticas e Medicinais do Instituto de Biotecnologia da Universidade de Caxias do Sul, o da Escola de Agroindústria em Fazenda Souza e a Sociedade Incubadora de Empresas de Base Tecnológica de Caxias do Sul. 
O programa dos pólos tecnológicos da Secretaria de Ciência e Tecnologia do estado do Rio Grande do Sul na década de 90: uma linha de ação estratégica de desenvolvimento regional/local

O Programa dos Pólos Tecnológicos da Secretaria de Ciência e Tecnologia do Estado do Rio Grande do Sul, vigente a partir do governo Simon (1987-1990), em aliança com o sistema de ensino superior do Rio Grande do Sul, está consubstanciado tanto nas concepções descentralizantes da gestão pública estadual como na concepção da construção das vantagens competitivas sistêmicas territoriais, e atribui crescente valorização às vantagens competitivas locais.

O Programa dos Pólos Tecnológicos, uma política pública de caráter estruturante ou estratégica - um vetor de desenvolvimento regional - está articulado à construção de visões de futuro das regiões. O número de pólos tecnológicos existente atualmente no estado é de dezesseis, estando suas ações distribuídas nas áreas metal-mecânica, agropecuária e alimentos e eletroeletrônica/informática. As áreas de atuação do Pólo de Modernização da Serra são a metal-mecânica, agropecuária e alimentos e eletroeletrônica/ informática.

Os pólos tecnológicos - formas com estrutura técnica - são como pontos de inovação difundidos pelo território enquanto fatores sistêmicos infra-estruturais, as externalidades para as empresas. Os fatores sistêmicos são compostos pelo conjunto de instituições e organizações públicas e privadas, entre elas, principalmente as universidades, os recursos humanos, financeiros e técnicos que configuram o sistema ciência-tecnologia-indústria (Coutinho; Ferraz, 1995, 19-21; Ferraz, 1995, p. 25-32; Becerra, 1994, p. 525-544; Feldman; Florida, 1994, p. 210-229; Maillat, 1997, p. 13-30).

A política científica e tecnológica pode afetar de modo significativo a competitividade dos lugares, ao contar, de um lado, com a infra-estrutura 
necessária (universidades, centros de pesquisa, serviços tecnológicos, etc.) e, de outro, oferecer estímulos (em particular crédito em condições favoráveis) à modernização contínua da indústria local (Ferraz, 1995, p. 25-32). Isso traz o conhecimento para o centro da análise da reestruturação produtiva e territorial através das políticas de inovação e dos pólos tecnológicos. Estar-se-ia, assim, engrenando as quatro esferas do capital, na medida em que um quarto fator de produção, o novo insumo informação, inaugura nova conotação de capital: o capital conhecimento (Costa Filho,1996, p. 7-8).

Guardadas as devidas especificidades no que tange às formas como as novas estratégias territoriais de desenvolvimento estão sendo implantadas nos países do Primeiro Mundo e nos países periféricos, concorda-se com Benko (1996) em que se, naqueles, ao Estado keynesiano corresponde o physical planning, no Brasil, ao Estado Desenvolvimentista correspondem, da mesma forma, os investimentos de vulto, a infra-estrutura estratégica (portos, aeroportos, estradas, eletricidade, telecomunicações) e zonas industriais. As novas tendências de planejamento, que rompem com os antigos métodos que requerem investimentos de vulto, direcionam-se para novos fatores: treinamento geral da população, qualificação profissional, dinamismo das empresas regionais, qualidade e quantidade dos serviços prestados às empresas, presença de centros de pesquisa, universidades, etc.

Os pólos tecnológicos - formas com funções estratégicas de conhecimento e programas de inovação em caráter de reconhecida importância estratégica para o desenvolvimento regional e local - encontram-se em fase embrionária no Rio Grande do Sul, não contendo produção industrial de alta tecnologia, ao menos na forma dos tecnopólos. No entanto, sua importância reside na difusão territorial nas diferentes regiões do estado, enquanto novas formas territoriais no âmbito da ciência e tecnologia, de forma dispersa pelo território e de forma diversa da clássica concentração na Região Metropolitana. Tal dispersão pelo território emerge através de um processo de geração endógena em escala local, de construção das infra-estru- 
turas através das próprias organizações locais, com apoio financeiro parcial por parte do Estado. ${ }^{3}$

\section{O mapa organizacional do território}

Boisier (1997, p. 12-18) sugere a confecção de um mapa organizaciona/4 do território. Esse mapa responderia a: a) quais são os atores; b) quais os procedimentos utilizados pelas diferentes organizações e instituições do lugar e c) quais os recursos (materiais, naturais, financeiros, humanos, conhecimento, etc.) com que conta o mesmo. Em sua proposta, Boisier une instituições e organizações que são essencialmente diferentes.

As instituições, numa abordagem genérica, significam um conjunto de regras e poderes de origem do Estado principalmente, ou mesmo civil, que se tornam referências para grandes parcelas da sociedade. Neste sentido, o Estado, em suas múltiplas faces e escalas, é a maior das instituições. Já as organizações, por sua vez, localizam-se no âmbito da sociedade civil principalmente, mas também do Estado. São constituídas pelo empresariado, pelos trabalhadores, pelas diversas formas de representação de interesses e de necessidades, pelos movimentos sociais, etc. Neste sentido, a organização representa um poder legítimo da sociedade, mas que não representa necessariamente uma referência institucional para amplos conjuntos da sociedade.

As organizações presentes no território, tanto públicas como privadas, podem ser indicadas sob uma determinada densidade organizacional atra-

3 O número de investigações que têm procurado examinar as repercussões do Programa dos Pólos de Modernização Tecnológica do Estado do Rio Grande do Sul no território estadual é crescente. Diferentes ângulos de análise podem ser encontrados em Schneider, 1997; Campis, 1997; Hanefeld, 2002. São significativas as pesquisas em andamento no programa de pós-graduação do Núcleo de Gestão da Inovação Tecnológica NITEC PPGEA - Programa de Pós Graduação em Administração da UFRGS, como Cesaro, 2000; Lima; Fracasso, 2002.

4 O conceito de mapa organizacional merece algumas considerações. Em primeiro lugar, Boisier (1997, p. 12-18) refere-se a mapa institucional, o que não é aqui tomado ipsis litteris, mas no sentido de organizacional, no sentido do conceito apontado por North (1990). Conforme Boisier, na prática, trata-se, em primeiro lugar, de confeccionar um cadastro organizacional (e institucional) tanto público como privado. Da mesma forma, ao conceituarem como densidade institucional, Amin, Thrift (apud Kirat; Lung, 1999) o fazem no sentido genérico, que engloba o Estado (instituição) e as organizações. Em segundo lugar, Boiser adota o conceito de mapa não no sentido cartográfico, mas no sentido de uma radiografia, uma visão de conjunto, uma determinada representação qualitativa ou quantitativa das instituições e organizações presentes no território. 
vés das articulações entre organizações e instituições. A densidade organizacional é conceituada como "a combinação de fatores, incluindo suas interações interinstitucionais e sinergia, uma representação coletiva por muitos corpos, um objetivo industrial comum e normas culturais e valores compartilhados" (Amin; Thrift apud Kirat; Lung, 1999, p. 31).

A densidade organizacional corresponde, portanto, às articulações entre as instituições e as organizações: as secretarias de governo estadual e local, as universidades e centros científicos, os serviços públicos, as empresas públicas, as organizações de caráter associativo. A freqüência de convênios entre as instituições e organizações indica o estágio de construção e/ou de consolidação de ações de implementação de vantagens competitivas locais.

A mensuração da densidade no mapa organizacional diz respeito às relações e articulações regionais (Franco, 1997, 1998) dos atores políticoterritoriais na implementação de programas estratégicos de caráter reestruturante e aos recursos com que conta o território, como aqueles referentes aos pesquisadores, aos investimentos financeiros em infra-estrutura de conhecimento, etc.

O cenário que associaria a descentralização de atribuições e funções em programas do pólo tecnológico com iniciativas do governo local em projetos reestruturantes de caráter endógeno, de forma mais completa se caracterizaria quando o Estado tem participação efetiva intermediária, em conjunto com o Corede e com as demais organizações locais e regionais privadas. As articulações do Estado com o poder local, numa forma de regulação intermediária, compõem o cenário de instituições públicas e organizações privadas que tendem a qualificar a densidade organizacional nas ações de caráter reestruturante.

Os principais atores político-territoriais locais/regionais envolvidos em programas do Pólo de Modernização Tecnológica da Serra são o empresariado, representado pelo poder hegemônico da Câmara de Indústria, Comércio e Serviços, aglutinadora das organizações corporativas dos segmentos produ- 
tivos; a Universidade de Caxias do Sul; os governos locais; organismos públicos e organizações civis atuantes em programas estratégicos/reestruturantes nas ações do Pólo, ou em outras ações inovadoras.

Os governos locais compõem apenas um elemento do conjunto de atores nos processos de reestruturação econômica e territorial. Em que pese um tradicional pequeno envolvimento com questões relativas ao desenvolvimento devidos, em parte à crise fiscal, os governos locais da região do Corede Serra, em suas relações institucionais com a universidade regional de Caxias do Sul (em cuja fundação são membros) e com o Corede (nos quais também são membros), têm passado a assumir maiores responsabilidades de organização e gerência em assuntos referentes aos seus territórios.

As responsabilidades dos governos locais na região do Corede Serra evidenciam-se não apenas na gestão de diversos serviços públicos assumidos no processo de descentralização de funções e atribuições. Tais responsabilidades localizam-se, por exemplo, na gestão de infra-estrutura básica de serviços no âmbito do processo de organização da Aglomeração Urbana do Nordeste do Rio Grande do Sul (Aune); em programas de fomento tecnológico - participação no Pólo de Modernização Tecnológico da Serra e na participação no projeto Tecnópole da Serra.

A presença de universidades e centros científicos - um dos fatores do desenvolvimento endógeno a que se refere Boisier (1997, p.12-18) - relaciona-se a políticas de inovação e reestruturação territorial no âmbito da escala local. Há relações entre os atores político-territoriais como sujeitos organizados do desenvolvimento endógeno e políticas de inovação direcionadas à construção da competitividade e das reestruturações produtivas dos locais e das regiões.

Entre os procedimentos - as relações e articulações locais e/ou regionais construídas pelos atores - utilizados pelas diferentes instituições e organizações da região, ressaltam-se aqueles que sustentam a gestão do desenvolvimento, isto é, o conjunto de formas de atuação do governo territorial 
e das organizações vinculadas precisamente à obtenção e ao seu estímulo do desenvolvimento.

Entre os recursos com que conta o território, apontam-se os investimentos públicos; os das organizações de ensino superior (formação de quadro de pesquisadores e infra-estrutura para geração e difusão de inovações) nos diversos segmentos do setor produtivo da região no entorno do Pólo de Modernização Tecnológica e, por fim, os dos atores corporativos empresariais e demais organizações associativas relacionadas à capacitação tecnológica.

\section{O Programa do Pólo Oleoquímico de Plantas Aromáticas e Medicinais do Instituto de Biotecnologia da Universidade de Caxias do Sul}

As ações que envolvem articulações regionais no Programa do Pólo Oleoquímico de Plantas Aromáticas e Medicinais-RS apontam para as interações da universidade com o setor produtivo e governos locais. O governo local do município de Campestre da Serra - localidade onde está instalado o Centro de Transferência de Tecnologia e Treinamento de Produtores Rurais de Campestre da Serra - é um dos casos inseridos nas articulações regionais no âmbito deste programa.

Em Campestre da Serra, 80\% dos produtores rurais são classificados como minifundiários, localizados em relevo irregular de difícil mecanização. Na concepção dos formuladores do Programa do Pólo Oleoquímico de Plantas Aromáticas e Medicinais-RS (do Instituto de Biotecnologia, Universidade de Caxias do Sul), esses pequenos agricultores, vocacionados para pequenas culturas, seriam potencialmente ideais para a produção de plantas aromáticas.

A formulação do programa aborda a necessidade de resolver a defasagem do setor agrícola, o êxodo rural, prevendo, para tanto, ações de reconversão agrícola, visando ao aumento de produtividade e de qualidade 
do produto final (Rio Grande do Sul, 1995). O processo de transformação nos padrões produtivos na pequena produção familiar na zona minifundiária do município principalmente é composto por duas etapas. Na primeira - a da diversificação -, o governo local incentiva a passagem da tradicional viticultura para a fruticultura, hortigranjeiros e flores com os objetivos de incrementar a geração de novos ganhos do trabalho familiar (agregação de valor), reduzir o êxodo rural e, mesmo, atrair o retorno de jovens à pequena agricultura familiar.

Na segunda etapa das transformações nos padrões produtivos, seguese o cultivo experimental de plantas aromáticas. Essa etapa se insere no processo de reestruturação produtiva via inovação tecnológica gerada no âmbito do Programa do Pólo Oleoquímico de Plantas Aromáticas e Medicinais-RS, em aliança estratégica do governo local com a Universidade de Caxias do Sul.

No projeto de plantas aromáticas, a segunda etapa de incentivos a transformações de padrões produtivos agrícolas - a reestruturação produtiva -, a ação do governo local é ampliada a partir da articulação regional no âmbito do Conselho Regional de Desenvolvimento e da inserção conveniada em programas previamente existentes na Universidade de Caxias do Sul na área de biotecnologia. O processo de regionalização da universidade (Pozenato, 1992, p. 9-12; Universidade de Caxias do Sul, 1992, 30 p.) implica o aprofundamento de suas relações com os governos locais, o que resulta, no caso de Campestre da Serra, na implantação do Centro de Transferência de Tecnologia e Treinamento de Produtores Rurais de Campestre da Serra.

A reestruturação parcial - em caráter experimental - da pequena agricultura familiar e pequena pecuária em terras de campo passa a dar-se com a introdução do cultivo de plantas aromáticas em áreas cujas características atendam ao critério da necessidade da inserção de pequenos agricultores em processo de empobrecimento, em função tanto da monocultura (uva, soja) como da pequena pecuária e do êxodo rural no programa. 
Os recursos humanos e de conhecimento (entre os elencados por Boisier, 1997) com que conta o território local de Campestre da Serra evidenciam-se principalmente à medida que a gestão do governo local empreende ações que buscam implementar ações de diversificação e de reestruturação produtiva a partir da articulação do local com os grandes centros inovadores de padrões produtivos no Exterior (Estados Unidos, Itália, Israel, Uruguai, Argentina).

Os recursos do território apontam, da mesma forma, para a experiência acumulada da pequena agricultura familiar, para a capacidade produtiva do pequeno estabelecimento, além das condições naturais, como o microclima apropriado para o cultivo de frutas. Os investimentos do governo local são de pequenos montantes, porém inovadores no sentido de implementar no lugar pequeno - na microlocalidade --, distante dos centros de poder de Estado, ações inovadoras que passam a diferenciar o local dos demais.

Os investimentos financeiros do governo local em tecnologia, especificamente no Centro de Transferência de Tecnologia e Treinamento de Produtores Rurais de Campestre da Serra, perfazem o perfil de pequeno projeto. ${ }^{5}$ Tal dimensão de pequenos investimentos, porém de significados novos, localiza-se no escopo das concepções assumidas nas teses do Fórum dos Conselhos Regionais de Desenvolvimento. Para essas teses, os lugares inserem-se numa crescente participação nas microdecisões, nas micropolíticas e nos pequenos projetos, que levam à definição e à constituição de múltiplos modelos e múltiplas formas de inserção de cada conjunto no processo global de desenvolvimento (Conselhos, 1999, p. 33).

As organizações civis locais, de caráter associativo, em Campestre da Serra, atuantes no município e envolvidas com a diversificação da pequena produção frutícola e com o Programa Oleoquímico, são, respectivamente,

5 O maior valor investido pela Prefeitura Municipal foi o de $\mathrm{R} \$ 50.000,00 \mathrm{em} 1994$ para a aquisição de terreno, trator e esteira. Em 1998 o valor foi de apenas R $1.694,70$ para aquisição de equipamentos e serviços diversos (Fonte: Prefeitura Municipal de Campestre da Serra). 
o Conselho de Desenvolvimento Comunitário de Campestre da Serra e a Associação dos Produtores de Plantas Aromáticas - Appam.

O Conselho de Desenvolvimento Comunitário de Campestre da Serra é uma organização associativa de caráter civil, fundada em 14 de março de 1991. Sua fundação com trinta integrantes (e a partir de 1994 com mais de duzentos e cinqüenta sócios, a maioria pequenos agricultores) tem como objetivo a instituição de apoio e desenvolvimento ao município. Citado como um projeto ao qual se vincula a emancipação do distrito em 1991, o Conselho é fundado como exigência do Fundo de Desenvolvimento Comunitário - Fundec - do Banco do Brasil, para a obtenção de financiamento de infra-estrutura de apoio aos agricultores, frigorificação e comercialização da produção frutífera do município. Esse Conselho é uma das formas associativas existentes no município, porém diretamente vinculado à expansão e melhoria da fruticultura.

A Associação dos Produtores de Plantas Aromáticas, uma entidade autônoma, pessoa jurídica de direito privado sem fins lucrativos, considera, em meados da década de 90, que aquele seria o momento para incentivar os produtores de plantas aromáticas e medicinais. As justificativas prendem-se, então, aos fatos da inexistência no mundo, tampouco no Brasil, de quantidades suficientes para a demanda da extração do óleo de plantas aromáticas e medicinais (Appam, s.d., p. 1).

Essa associação, no entanto, além de aglutinar um pequeno número de cultivadores, ao contrário das expectativas iniciais do programa, não é constituída por agricultores minifundiários, mas por pequenos pecuaristas com uma tradição agrícola muito diferenciada daquela dos agricultores minifundiários. Os pequenos fazendeiros que iniciam as atividades no projeto são proprietários de áreas que variam entre 48 a 400 hectares. O Sítio da Amizade, na localidade de Guacho, por exemplo, é a primeira pequena fazenda a adotar o cultivo de alecrim. Este estabelecimento em terras de campo, na zona de transição campo-colônia, caracteriza-se tanto pela pe- 
quena agropecuária familiar como pelo alto êxodo rural familiar e pela inviabilidade da pequena agricultura.

As articulações no âmbito das ações do Programa Oleoquímico no lugar, através do governo local do município de Campestre da Serra ao Corede Serra, Pólo de Modernização Tecnológica e Universidade de Caxias do Sul, apontam para as relações político-institucionais locais com as instâncias intermediárias regional-locais. Tais articulações a essas instâncias representativas do poder hegemônico regional e suas respectivas capacidades técnico-científicas localizadas em Caxias do Sul apontam para a escala regional-local como a instância política e tecnicamente viabilizadora de ações inovadoras em tecnologia, como as do governo local de Campestre da Serra, além dos recursos repassados pela Secretaria de Ciência e Tecnologia para os laboratórios da universidade.

O Instituto de Biotecnologia da Universidade de Caxias do Sul busca, através de suas pesquisas, resolver problemas regionais e transferir tecnologias. Valendo-se da experiência adquirida com o grupo de Farmacognosia e Produtos Naturais da Facultad de Química da Universidad de La Republica Oriental del Uruguay, na área de óleos essenciais, o instituto tem desenvolvido várias linhas de trabalho relacionadas com as plantas aromáticas. Em particular, uma linha de pesquisa encontra-se focalizada no desenvolvimento de tecnologias de produção, avaliação e transferência para o setor produtivo-industrial de produtos e processos de interesse econômico no setor oleoquímico de plantas aromáticas e medicinais (Universidade de Caxias do Sul, 1999, p. 3).

As atividades de pesquisa são conduzidas no Instituto de Biotecnologia, num conjunto de laboratórios, por um quadro de pesquisadores responsáveis pelo Programa Oleoquímico e pela coordenação do programa de pósgraduação (Mestrado) próprio da Universidade de Caxias do Sul, no total de nove pesquisadores. Os investimentos financeiros e disponibilização da infraestrutura no programa demonstram que a Universidade de Caxias do Sul 
tem participação majoritária nos investimentos diretos e indiretos, em comparação aos efetuados pela Secretaria de Ciência e Tecnologia do Estado do Rio Grande do Sul. ${ }^{6}$

Para Wanderley M. da Costa, ex-diretor geral da organização social Bioamazônia e criador do Probem - Programa Brasileiro de Ecologia Molecular para o Uso Sustentável da Biodiversidade da Amazônia -, o Programa Oleoquímico do Instituto de Biotecnologia da Universidade de Caxias do Sul é a única experiência do gênero no país, já que não existe nenhum pólo de biotecnologia com tais características. Para Costa:

O Bio-Minas e o Bio-Rio, por exemplo, concentram-se na área farmacêutica, enquanto o do Ceará, em fitoterápicos. Os demais, liderados pela Embrapa, estão na área dos alimentos convencionais. O que está sendo construído em Manaus (pela Bioamazônia) é o único planejado para atuar em todas as áreas, isto é, dos farmacêuticos, fitoterápicos, aromatizantes, flavorizantes, insumos para cosméticos, etc. Até o momento, entretanto, o de Caxias é o mais avançado projeto no setor (depoimento; 21 nov. 2001).

Os convênios de cooperação técnico-científica - indicadores da densidade organizacional - entre o Instituto de Biotecnologia, universidades, empresas privadas e órgãos públicos representam a articulação extra-regional para qualificar e viabilizar procedimentos técnico-científicos e comerciais. As atribuições da "Universidad de la República - Montevidéo", no programa, são de disponibilizar tecnologias de análises laboratoriais.

As atribuições da Unicamp consistem na caracterização dos óleos essenciais de espécies de plantas já cultivadas e/ou a serem introduzidas na Serra gaúcha, através da identificação e quantificação dos seus principais componentes, além de estudos de mercado (Unicamp, 25 jun. 1997). As

6 Entre 1996 e 1999, os investimentos no Programa Pólo Oleoquímico foram nos montantes de R\$ 802.991,00 pela Universidade de Caxias do Sul e de R\$ 449.275,00 pela Secretaria Estadual de Ciência e Tecnologia. (Fonte: Processos da Secretaria de Ciência e Tecnologia do Estado do Rio Grande do Sul, de 1995 a 1998). 
atribuições da PUCRS (Porto Alegre) são de capacitação e desenvolvimento de processos de extração de óleos essenciais a partir de plantas aromáticas e/ou matérias-primas de natureza vegetal (PUC/UCS, 4 jun. 1999). As empresas privadas que passam a atuar no programa perfazem tanto o universo de fornecedores de sementes como o de capitais locais entrantes no ramo de óleos essenciais. O Estado, nas escalas estadual e federal, tem-se mostrado presente nesse programa com recursos de incentivo à pesquisa científica.

Apesar de a experiência em Campestre da Serra com pequenos pecuaristas dissociar-se das asserções originais do programa, de ser adequado para minifúndios, o mesmo se encontra em expansão em áreas minifundiárias no município de Morro Reuter (região do Corede Paranhana), $70 \mathrm{~km}$ ao sul de Caxias do Sul. Neste sentido, o governo local tem incentivado o cultivo de lavanda junto a um grupo de mais de sessenta pequenos agricultores, com a distribuição de mais de trinta mil mudas vindas da França, como uma alternativa ao cultivo da batata-inglesa, produto de baixo ganho para o pequeno agricultor.

Os projetos do governo local de Morro Reuter são a extração de óleos e essências e a instalação de uma minidestilaria e atração turística. O governo local paga a metade do valor das mudas. O prefeito municipal busca o modelo no sul da França onde a lavanda e seus derivados são grandes atrações turísticas, e em Bariloche, na Argentina. "Estamos numa rota turística, entre Caxias e Porto Alegre e próximos de Gramado e Canela. Vamos ingressar nela" (Pólo, 27 out. 1999, p. 4).7 O cultivo de plantas essencieiras e a sua extração encontram-se em processo de expansão, envolvendo vários governos locais, o que aponta para a importância dos governos locais na difusão de inovações tecnológicas. Conforme a imprensa, está ocorrendo a formação de núcleos identificados com determinadas espécies - o carro

7 “As esperanças dos agricultores são de abastecer o mercado nacional. O quilo do óleo da planta híbrida é vendido no mercado mundial a US\$44,21. O preço da lavanda pura, que já floresce em Morro Reuter, salta para US\$122,23. Diante dos custos de cultivo, a previsão é de que somente em 2001 seja ampliada a área de cultivo e se iniciem as vendas" (Cardoso, 13 fev. 2000, p. 31). 
chefe de Campestre da Serra será o alecrim; de Morro Reuter, lavanda; de Lagoa Vermelha, camomila; de Três Passos, citronela; de Caxias do Sul, sálvia e menta (Pólo, 27 out. 1999, p. 4).

\section{O Programa Escola de Agroindústria Fazenda Souza}

O Programa Escola de Agroindústria tem como principal finalidade a difusão de tecnologias de produção, industrialização, administração e gerenciamento de pequenas e médias agroindústrias, promovendo e proporcionando a profissionalização do agricultor, na concepção de seus formuladores. Seu objetivo é proporcionar maior número de opções de ganhos ao pequeno agricultor (agregação de valor à produção), permitindo também o aproveitamento industrial dos excessos e resíduos da produção, sem acarretar impactos negativos ao ambiente.

As estruturas existentes nas pequenas propriedades para a fabricação de vinho poderiam, na concepção original do projeto, com algumas modificações e treinamento de pessoal, adaptar-se ao fabrico de doces caseiros, como geléias ou doces em pasta, sucos, molhos e picles e até desidratados. "Na região da Serra, que sempre serviu de modelo de desenvolvimento para a pequena propriedade, é de vital importância a sua industrialização, seja de forma individual ou através dos condomínios rurais" (Conselho Regional de Desenvolvimento, 1993, p.94-96).

O Programa Escola de Agroindústria em Fazenda Souza, ao promover a agregação de valor ao trabalho na pequena propriedade, não se caracteriza, no entanto, como de inovação tecnológica, mas como de inovação de técnicas de agroindustrialização. O programa contém grande número de atores institucionais presentes, o que reforça a tese das articulações regionais e de escalas de poderes, em alianças estratégicas entre organizações civis e instituições públicas em escalas diferentes, locais, regional-locais e nacional, nos pequenos projetos de desenvolvimento. 
Para a implementação desse programa, forma-se um grupo de trabaIho multi-institucional de técnicos e pesquisadores da Universidade de Caxias do Sul; Universidade Federal de Pelotas; Centro de Pesquisa de Fruticultura de Clima Temperado da Embrapa - Pelotas; Emater - setor de agroindústria; Secretaria Municipal de Caxias do Sul e Estação Experimental de Caxias do Sul, para promover a pesquisa e transferência de tecnologia da agroindústria aos agricultores da região Nordeste do estado.

As atribuições do governo local de Caxias do Sul (na gestão Vanin \& Spiandorello, 1993-1996) ${ }^{8}$ em apoio ao programa de agroindústria comprometem-se com a construção de instalações neste centro. Além dos investimentos em obras de infra-estrutura, as atribuições do governo local de Caxias do Sul, entre outras, são de caráter didático dos cursos e seleção, no município e região, de agricultores, com participação como membro do Colegiado do Conselho Técnico-Administrativo (Rio Grande do Sul, 11 out. 1998). A Emater, em conjunto com a Prefeitura Municipal, assume as atribuições de execução das obras de implantação da agroindústria e da organização dos grupos de técnicos extensionistas e produtores rurais a serem treinados.

Já na escala do governo estadual, à Emater e à Ascar cabe, em conjunto com a Estação Experimental de Caxias do Sul/Fepagro, a promoção de cursos para os agricultores selecionados. As atribuições da Secretaria de Ciência e Tecnologia são de prestar apoio institucional para execução dos cursos, visando maximizar o processo de aprendizagem no Centro de Treinamento de Agricultores em Fazenda Souza e colaborar com os demais partícipes na articulação com instituições públicas e privadas, nacionais e/ ou internacionais, objetivando a obtenção de recursos financeiros, materiais e humanos, que possam contribuir para a execução do objeto do convênio (Rio Grande do Sul, 11 out. 1998j).

A atual administração da Frente Popular no município de Caxias do Sul (1997/2000; 2000-2003) desenvolve o Projeto Copas para a promoção da

8 A gestão 1993-1996, tendo à frente o prefeito Mário Vanin e o vice-prefeito, Francisco de Assis Spiandorello, é eleita através da coligação da UDC - União Democrática por Caxias, composta pelos partidos PL, PTB, PSDB e PFL. 
agroindustrialização. A ação baseia-se no estímulo ao surgimento da agroindústria de pequeno porte com inspeção municipal, aproveitando o conhecimento dos agricultores na produção de produtos coloniais. O objetivo é, da mesma forma que o Programa Escola de Agroindústria Fazenda Souza, agregar valor aos produtos agrícolas, garantindo maior renda aos agricultores, gerar emprego e, conseqüentemente, melhorar a qualidade de vida dos produtores.

O Projeto Copas ocorre através do financiamento do fundo rotativo municipal, assistência técnica e de comercialização, cursos de agroindustrialização, inspeção municipal e a redução da burocracia e custos na implementação da agroindústria (Caxias do Sul, s.d.). O projeto visa retirar os pequenos produtores da ilegalidade e proporcionar a manutenção do trabalho e incremento da renda.

O Programa Escola de Agroindústria em Fazenda Souza, ao promover a difusão de técnicas de agroindustrialização entre pequenos agricultores, faz isso de forma a incorporar um conjunto de atores representativos de instituições públicas e organizações civis. Ao mesmo tempo, incorpora, nas ações, investimentos e recursos da universidade comunitária privada, do governo local e estadual e recursos de conhecimentos de universidades e centros de pesquisa públicos federais. As ações do Projeto Copas dão-se pela iniciativa do governo local, que, assim, dá prosseguimento à mesma linha de ação - a agregação de valor à pequena produção agrícola -, resguardada a dimensão da gestão que se restringe a ações do Estado na escala local, apoiado pelo Orçamento Participativo do Município de Caxias do Sul.

\section{O programa Sociedade Incubadora de empresas de base tecnológica de Caxias do Sul}

A criação e implementação do Programa Sociedade Incubadora de Empresas de Base Tecnológica de Caxias do Sul - uma sociedade civil, de 
direito privado, sem fins lucrativos - acontece no âmbito de uma estratégia de desenvolvimento que privilegia a inovação de processos, ao mesmo tempo em que cria as condições para favorecer o aparecimento de novas empresas e de novos produtos com maior densidade tecnológica. Tal estratégia é implementada pela organização local Câmara da Indústria, Comércio e Serviços de Caxias do Sul, governo local, organização regional Fundação Universidade de Caxias do Sul e governo do Estado. Trata-se de um programa com alta densidade organizacional, que procura desenvolver ações no sentido da modernização da região da Serra para competir em igualdade de condições com outras regiões. Os projetos preferenciais localizam-se nas áreas de eletroeletrônica, informática, metal-mecânica, biotecnologia e novos materiais.

Na concepção do programa da Sociedade, consubstanciam-se os objetivos regionais do Pólo de Modernização Tecnológica da Serra, os quais privilegiam a inovação de processos, articulando os setores privado, público e técnico-científico no desenvolvimento de pesquisa de interesse regional e de processos de transferência de tecnologia. Um dos objetivos do PMTSerra é incentivar a inovação do tecido industrial, tanto pela transferência de tecnologia às empresas já existentes quanto pela criação de novas empresas de base tecnológica (Pólo de Modernização Tecnológica da Serra/ Universidade de Caxias do Sul, 1997, p. 7).

Para Cabral (1998, p.303-311), o modelo de gestão da Sociedade Incubadora não é comum. De forma diferente dos convênios, a responsabilidade de cada parceiro é assumida por tempo indeterminado e definitivamente solidária. A aliança estratégica entre a Fundação Universidade de Caxias do Sul, o governo local de Caxias do Sul e a Câmara de Indústria, Comércio e Serviços envolve comprometimentos mútuos. Estes visam propiciar condições que favoreçam a criação e consolidação de micro e pequenas empresas, a promoção do desenvolvimento socioeconômico da cidade e região, o aumento da renda e a criação de novas oportunidades de traba- 
Iho, por meio da implantação de atividades que aproveitem os recursos e potencialidades locais.

Para a consecução de tais objetivos, a Fundação da Universidade, o Município e a CIC comprometem-se, em meados da década de 90, a buscar fontes de financiamento e a realizar ações que visam materializar a inovação das empresas nascentes e das já existentes que necessitem atingir nível tecnológico e gerencial mais moderno e competitivo (Universidade de Caxias do Sul, 1996). As competências das organizações e do governo local de Caxias do Sul consistem em contribuir com recursos para a Sociedade Incubadora Tecnológica.

O governo local apóia as iniciativas de implantar-se a Sociedade Incubadora Tecnológica desde 1992, com base no exame da experiência das tecnópoles francesas. A partir de então, o governo local assume a responsabilidade de tornar-se um dos atores empreendedores do projeto, apostando na mudança de enfoque do poder público sobre a necessidade de apoio a empreendimento dessa natureza.

Os recursos financeiros, diretos e indiretos, investidos na Sociedade provêm majoritariamente da Fundação Universidade de Caxias do Sul e do Programa dos Pólos Tecnológicos da Secretaria de Ciência e Tecnologia. A participação do governo local é minoritária, limitada ao estipulado pela lei anual do Orçamento do Município de Caxias do Sul.

Os três programas examinados no âmbito do Pólo de Modernização Tecnológica da Serra demonstram a multiplicidade de poderes locais, articulados à escala regional-local, principalmente no sentido de implementar programas de caráter reestruturante. Tais programas, no âmbito do Pólo de Modernização Tecnológica, da Universidade de Caxias do Sul e do Corede Serra, não compõem, todavia, todo o universo de ações inovadoras. Tais ações ou estratégias de bloco (Borba, 1999) compõem-se de uma gama maior, implementadas pelas organizações privadas empresariais, com articulações diversas com vários atores e escalas de poder. Em tais ações inova- 
doras, o governo local e a universidade encontram-se invariavelmente presentes. Entre esta ampla gama, tem relevância o Pólo de Mecatrônica e Autotrônica.

O Pólo de Mecatrônica e Autotrônica em Caxias do Sul, por exemplo, é resultado de ações das organizações privadas - $\mathrm{CIC}$, em alianças estratégicas com o Senai/Fiergs, Fundação Universidade de Caxias do Sul e governo local. Este assume basicamente as ações de apoio político e de fornecimento de obras de infra-estrutura física, o que se evidencia em pequena participação em termos de valores-investimento. No entanto, a alegação é de que o governo local tem "(...) uma participação muito importante. Mesmo porque o poder local, o município e outras entidades da sociedade, no caso específico aqui a Câmara da Indústria e Comércio, sempre fizeram um trabalho muito entrosados, permanentes" (Vanin, ex-prefeito de Caxias do Sul, entrevista, mar. 2000).

Para Borba, o empresariado caxiense tem investido no que conceitua de estratégias de bloco, isto é,

(...) aquelas que visam ao desenvolvimento de todo o parque industrial e de suas empresas como um conjunto articulado: o Centro Tecnológico de Mecatrônica (e Centro de Autotrônica), a Escola Técnica de Moda (na UCS) e Centro Tecnológico da Indústria Moveleira (Cetemo) em Bento Gonçalves (1999, p. 48).

As estratégias de bloco são aquelas que se relacionam por similaridade e pela origem comum nas ações no empresariado e na ação conjunta entre estes e a universidade. Esse conjunto de ações pode ser classificado como reestruturantes por incidir sobre a criação de infra-estruturas estratégicas na perspectiva de construção de ambientes competitivos. Nesse sentido, as estratégias de bloco aproximam-se das ações do Pólo de Modernização Tecnológica da Serra com ações imbricadas entre si, tendo, porém, especificidades distintas de atuação. 


\section{Considerações finais}

Ao se analisarem algumas ações estratégicas implementadas pelo Estado (poder público estadual e municipal) e por organizações da sociedade civil, especificamente no que tange às políticas públicas de Ciência e Tecnologia no estado do Rio Grande do Sul enquanto políticas territoriais, evidencia-se um conjunto de atores hegemônicos na região e nos locais de pesquisa envolvidos com ações de inovação tecnológica - o empresariado. Um dos dados novos revelado na análise é o Estado na escala local: os governos locais, que passam a assumir tais ações enquanto política pública associada a organizações civis.

Descentralização política e desenvolvimento local, aqui tomados como ações do Pólo de Modernização Tecnológica da Serra, encontram-se efetivamente associados. O caso examinado confirma as asserções de Boisier e Sabatini et al. (1994, p. 351-389), de que a descentralização, particularmente a descentralização territorial, é uma condição necessária para a obtenção da transformação produtiva.

Entretanto, há que se considerar que os lugares refletem com toda a intensidade as assimetrias do poder local, as idiossincrasias e as disputas em torno de projetos hegemônicos. O empresariado da região compõe um conjunto de atores capaz de articular uma vasta região em seu entorno, demonstrando articulações políticas, capacidade de atração de investimentos oriundos de processos políticos descentralizantes, como é o caso do Programa dos Pólos Tecnológicos da Secretaria de Ciência \& Tecnologia para seus territórios.

A descentralização político-administrativa e a redemocratização no Brasil, ao promoverem a reforma do Estado no sentido de transferir funções e recursos - apontados agora como insuficientes pelos governos locais -, ao mesmo tempo em que trazem estes governos para a atenção das populações como o gestor mais próximo, expõem-nos aos cenários da abertura 
econômica. Tradicionalmente envolvidos com os serviços urbanos, os governos locais examinados têm tratado efetivamente de incorporar-se a ações de caráter reestruturante, a partir de formas estratégicas como o Pólo de Modernização Tecnológica da Serra, ou a agregar-se em projetos de alta tecnologia do empresariado.

O empreendedorismo das gestões dos governos locais examinados emerge como a capacidade de articular-se com os atores econômica e politicamente hegemônicos do lugar. Tais ações tendem a imprimir novos usos aos territórios dos lugares, considerando-se que aquelas são dotadas de capacidades de difusão de inovações a partir de infra-estruturas estratégicas dotadas de conhecimento.

A alta densidade organizacional representada pelos programas analisados demonstra, em boa medida, que os governos locais, muito embora integrados às ações de inovação, não são os principais atores enquanto investidores. Tais investimentos têm sido oriundos da universidade comunitária privada examinada e do Estado. Neste segundo caso, os aportes de fundos provindos de políticas públicas, examinadas entre 1991 e 1998, representam, no âmbito do Programa dos Pólos Tecnológicos, compatibilidades com a capacidade de negociação dos atores locais/regionais e de fazer-se representar nos mecanismos de democracia participativa com projetos significativos no cenário das tendências das reestruturações produtivas e territoriais

Da mesma forma, os lugares examinados evidenciam também que se torna progressivamente sem sentido tomar-se o caso isolado do local - no caso examinado, equivalente a municípios - considerando-se que a capacidade de aglutinação dos governos locais e das organizações sobre territórios mais amplos confere-lhes capacidades competitivas, tendendo a diferenciálos dos demais lugares. Nesse sentido, o aprofundamento dos investimentos industriais e dos recursos estratégicos (como as infra-estruturas físicas e informacionais) tende a agravar o cenário das desigualdades inter-regionais no Rio Grande do Sul. Assim, as teses das descentralizações de poder não 
correspondem às desconcentrações produtivas, pois aos arranjos políticoterritoriais não se seguem, nos tempos desejados, os arranjos econômicoespaciais. A territorialização da dinâmica política é mais lenta que a dinâmica econômica.

Por fim, reconhece-se que a implementação das diversas capacidades inovadoras nos lugares examinados enquanto uma das múltiplas dimensões das reestruturações econômicas e territoriais, exerce capacidades efetivas de mudanças de formas nos territórios. Tais dimensões reestruturadoras, concentradas no eixo Porto Alegre-Caxias do Sul apontam, no entanto, para a necessidade de geração de políticas públicas de aprofundamento dos processos políticos, de desconcentração de ciência e tecnologia nos diversos lugares do território estadual.

\section{Referências}

ANTONELLI, Cristiano; FERRÃO, João (coords.). Comunicação, conhecimento colectivo e inovação. As vantagens da aglomeração geográfica. Lisboa: Instituto de Ciências Sociais da Universidade de Lisboa, 2001.227 p.

ASSOCIAÇÃO dos Produtores de Plantas Aromáticas e Medicinais de Campestre da Serra (Appam). Estatuto. Campestre da Serra, 1997. 9 p.

BANDEIRA, Pedro Silveira. A economia da região Sul. In: AFFONSO, Rui de Britto Álvares; SILVA, Pedro Luis. (Orgs.). Federalismo no Brasil. Desigualdades regionais e desenvolvimento. São Paulo: Fundap/Unesp. 1995. p.225-251.

BARQUERO, Antonio Vázquez. Desenvolvimento endógeno em tempos de globalização. Porto Alegre: Fundação de Economia e Estatística; UFRGS Editora, 2001. 278 p.

BECERRA, José Luis Moreno. Innovación tecnológica y desarrollo regional: hacia una más eficaz interrelación universidad-sociedad. In: Territorios en transformación: análisis y propuestas. Madrid: Fondo Europeo de Desarrollo 
Regional/Consejo Nacional de Investigaciones Científicas, 1994. p 523-544.

BECKER, Bertha K.. O uso político do território: questões a partir de uma visão do terceiro mundo. In: BECKER, Bertha K.; COSTA, Rogério H. da.; SILVEIRA, Carmen B.. (Orgs). Abordagens políticas da espacialidade. Rio de Janeiro: UFRJ, 1983. p. 1-8.

BECKER, Bertha K.. A crise do Estado e a região - a estratégia da descentralização em questão. In: BECKER, Bertha K. (Org). Ordenação do território: uma questão política? Exemplos da América Latina. Rio de Janeiro: UFRJ, 1984. p. 1-36.

BECKER, Bertha K.. A geografia e o resgate da geopolítica. Revista Brasileira de Geografia, Rio de Janeiro, v. 50, t.2, p. 99-125,1988. Número especial.

BECKER, Bertha K.. Modernidade e gestão do território no Brasil: da integração nacional à integração competitiva. Espaço e Debates. São Paulo, no 31, p. 47-56, 1991.

BECKER, Bertha K.. A geopolítica na virada do milênio: logística e desenvolvimento sustentável. In: CASTRO, Iná E. de et al. (Orgs). Geografia: conceitos e temas. Rio de Janeiro: Bertrand Brasil, 1995. p. 271-307.

BENKO, Georges. Economia, espaço e globalização na aurora do século XXI. São Paulo: Hucitec, 1996. 266 p.

BOISIER, Sérgio; SABATINI, Francisco et al. La descentralización: el eslabón perdido de la cadena; transformación productiva con equidad y sustentabilidade. In: Territorios en transformación. Análisis y propuestas. Madrid: Fondo Europeo de Desarrollo Regional/Consejo Superior de Investigaciones Científicas, 1994. P. 351-389.

BOISIER, Sérgio; LIRA, Luis et al. Sociedad civil, actores sociales y desarrollo regional. Santiago de Chile: Ilpes/Cepal, 1995. 59 p.

BOISIER, Sérgio. Em busca do esquivo desenvolvimento regional: entre a caixapreta e o projeto político. Planejamento e políticas públicas. Rio de Janeiro, no 13, p. 111-145, jun. 1996.

BOISIER, Sérgio. El vuelo de una cometa. Una metafora para una teoría del desarrollo territorial. Santiago do Chile: Ilpes/Cepal, 1997. 34 p. 
Sociologias, Porto Alegre, ano 6, no 11, jan/jun 2004, p. 148-183

BOISIER, Sérgio. Desarrollo (local): de qué estamos hablando. In: BECKER, Dinizar; BANDEIRA, Pedro S. Desenvolvimento local-regional. Determinantes e desafios contemporâneos. Vol 1. Santa Cruz do Sul: EDUNISC, 2000. p. 151-185.

BORBA, Sheila V. Impactos sociais e territoriais da reestruturação econômica no Rio Grande do Sul. Impacto urbano das transformações da economia industrial na Região Nordeste do Rio Grande do Sul. Porto Alegre: FEE, 1999.108 p.

BRAGA, Tania Moreira. "Desenvolvimento local endógeno" e suas aplicações na formulação de políticas municipais. In: Encontro da Associação Nacional de PósGraduação e Pesquisa em Planejamento Urbano e Regional, 8, maio 1999, Porto Alegre. Anais. Porto Alegre: Propur/UFRGS, 1999. 1 CD.

BREITBACH, Aurea C. O desenvolvimento da região de Caxias do Sul. In: Anais. ENCONTRO ESTADUAL DE GEOGRAFIA. Os novos contextos urbano-industriais e turísticos, 21, Caxias do Sul, junho 2001. Caxias do Sul: EDUCS / AGB, 2001, p.113-125.

CABRAL, Rosângela I. Incubadora Tecnológica de Caxias do Sul: uma experiência multiinstitucional de implantação. In: Anais. SEMINÁRIO NACIONAL DE PARQUES TECNOLÓGICOS E INCUBADORAS DE EMPRESAS, 8, Belo Horizonte, set. 1998. Belo Horizonte: Anprotec, 1998, p. 303-311.

CAMPIS, Luiz Augusto Costa. O Pólo de Modernização Tecnológica do Vale do Rio Pardo. Uma análise crítica. Redes, Santa Cruz do Sul, v. 2, no 1, p. 9-36, jul. 1997.

CARDOSO, Fabrício. Morro Reuter cobre os campos de lavanda. Zero Hora, Porto Alegre, 13 fev. 2000, p. 31.

CASTRO, Iná E. de. O problema da escala. In: Geografia: conceitos e temas. Rio de Janeiro: Bertrand-Brasil, 1995. p.117-140.

CAXIAS DO SUL. Cadastro rural do município de Caxias do Sul. Caxias do Sul: Prefeitura Municipal, 1996, 18 p.

CESARO, Nestor Henrique de. Avaliação de impactos do projeto de piscicultura do Pólo de Modernização Tecnológica do Médio Alto Uruguai. 2000. Dissertação (Mestrado em Administração). Programa de Pós Graduação em Administra- 
ção, Universidade Federal do Rio Grande do Sul, Porto Alegre.

CONSELHO REGIONAL DE DESENVOLVIMENTO DA SERRA. Projeto desenvolvimento da agroindústria da região Nordeste do Estado. Caxias do Sul, 1993. 29 p.

CONSELHO REGIONAL DE DESENVOLVIMENTO DA SERRA. Uma trajetória de participação de 1991-1998. Caxias do Sul: Gráfica da UCS, 1998. 160 p.

CONSELHOS REGIONAIS DE DESENVOLVIMENTO DO RIO GRANDE DO SUL. Pró-RS: estratégias regionais pró-desenvolvimento do RS. Lajeado: Fates Editora, 1999. 92 p.

COSTA, Wanderley M. O Estado e as políticas territoriais no Brasil. São Paulo: Edusp/Contexto, 1988.83 p.

COUTINHO, Luciano; FERRAZ, João Carlos. Estudo da competitividade da indústria brasileira. 3ํㅗㄹ ed., Campinas: Papirus/Editora da Unicamp. 1995. 510 p.

DINIZ, Clélio Campolina Reversión de la polarización y reconcentración regional en Brasil. In: Territorios en transformación. Madrid: Fondo Europeo de Desarrollo Regional/Consejo Superior de Investigaciones Científicas, 1994. p. 239-265.

FELDMAN, Maryann P.; FLORIDA, Richard. The geographical sources of innovation: technological infrastructure and product innovation in the United States. Annals of the Association of American Geographers, v. 84, no2, p. 210229, 1994.

FERRÃO, João. Colectividades territoriais e globalização: contributos para uma nova acção estratégica de emancipações. Inforgeo. Lisboa: no9-10, p. 65-75, 1995.

FERRÃO, João. Educação, sociedade cognitiva e regiões inteligentes: uma articulação promissora. Inforgeo. Lisboa, p. 97-104, 11 dez. 1996.

FERRAZ, João Carlos et al. Made in Brazil. Desafios competitivos para a indústria. Rio de Janeiro: Campus. 1995.386 p.

FIORI, José Luis. Em busca do dissenso perdido. Ensaios críticos sobre a festejada crise do Estado. Rio de Janeiro: Insight Editorial, 1995. 245 p. 
FRANCO, Maria Estela dal Pai. A produção de pesquisa no Rio Grande do Sul. Uma questão político-educacional In: FRANCO, Maria Estela Dal Pai (org). Universidade, pesquisa e inovação: o Rio Grande do Sul em perspectiva. Passo Fundo: Ediupf, Porto Alegre: Edipucrs, 1997. p. 19- 46.

FRANCO, Maria Estela dal Pai (Coord.). Condições de produção de pesquisa: quadro das universidades do Rio Grande do Sul. ljuí: Ed Unijuí, 1998. 253 p.

GUIMARÃES NETO, Leonardo. Estudo sobre a questão regional: pequeno balanço da segunda metade dos anos 80 e da primeira metade dos anos 90. Curitiba: Ilpes/Ipardes, 1995. 13 p.

HANEFELD, Alexandro Oto. Pólos de modernização tecnológica e desenvolvimento regional: o caso do Pólo de Modernização do Vale do Rio Pardo, Rio Grande do Sul, Brasil. Santa Cruz do Sul: EDUNISC, 2002. 105 p. (Série conhecimento. Teses e dissertações; 11)

HERÉDIA, Vânia. Novos contextos urbano-industriais. In: ENCONTRO ESTADUAL DE GEOGRAFIA. Anais. Os novos contextos urbano-industriais e turísticos, 21, Caxias do Sul, junho 2001.Caxias do Sul: EDUCS / AGB, 2001, p.327-335.

KIRAT, Thierry; LUNG, Yannick. Innovation and proximity. Territories as loci of collective learning processes. European Urban and Regional Studies, London, v. 6, nำ1, p. 27-38, 1999.

LAHORGUE, Maria Alice. Economia Regional. UFRGS, 1999. Notas de curso.

LEFEBVRE, Henri. Espacio y política. Barcelona: Ediciones Península, 1976. 159 p.

LIMA, M. A. Barbosa; FRACASSO, E. M. Impacto de Programa Público de Inovação Tecnológica no Desenvolvimento Sustentável Regional. In: XXII SIMPÓSIO DE GESTÃO DA INOVAÇÃO TECNOLÓGICA. Salvador, 6 a 8 de Novembro 2002. 1 CD Rom.

MAILLAT, Denis. Milieux innovateurs et nouvelles genérations de politiques regionales. In: Políticas de inovação e desenvolvimento regional e local. Lisboa: Instituto de Ciências Sociais da Universidade de Lisboa, 1997. p. 13-30.

MARTIN, José Carpio. El desarrollo local. Claves para la promoción del desarrollo. 
São Paulo: USP/FFLCH, 1996. 23 p.

MATTOS, Carlos. La crisis de la enseñanza urbano-regional y la evolución de las teorías del crecimiento económico. In: ENCUENTRO DE POSGRADOS SOBRE DESARROLLO Y POLÍTICAS TERRITORIALES Y URBANAS DE LOS PAÍSES DEL CONO SUR. Anais. 2 Montevidéu, 1997. Secção Uruguaya de la Red Iberoamericana de Investigadores sobre Globalizacion y Territorio. Montevidéu, 21-22 ago.1997. 14 p.

NORTH, Douglas. Institutions, institutional change and economic performance. Cambridge Universtiy Press, 1990. 152 p.

POZENATO, José Clemente. Sobre o conceito de Universidade Regional. In: Universidade de Caxias do Sul. A regionalização da Universidade: Conceitos e perspectivas. Caxias do Sul, 1992, p. 9-12.

PÓLO DE MODERNIZAÇÃO TECNOLÓGICA DA SERRA/UNIVERSIDADE DE CAXIAS DO SUL. Centro de Transferência de Tecnologia e Treinamento de Produtores Rurais (fase I). Relatório final. Caxias do Sul: Corede Serra/UCS/IB, 1996. 25 p.

PÓLO DE MODERNIZAÇÃO TECNOLÓGICA DA SERRA/UNIVERSIDADE DE CAXIAS DO SUL. Projeto de implantação da Incubadora de Empresas de Base Tecnológica de Caxias do Sul. Caxias do Sul, jun. 1997. 24 p.

PONTIFÍCIA UNIVERSIDADE CATÓLICA/UNIVERSIDADE DE CAXIAS DO SUL. Termo aditivo no 03 ao convênio de cooperação entre a Pontifícia Universidade Católica do Rio Grande do Sul e a Universidade de Caxias do Sul. Porto Alegre, 4 jun. 1999. 5 p.

PÓLO oleoquímico se espalha por municípios gaúchos. Correio Riograndense. Caxias do Sul, 27 out. 1999. p. 4

RAFFESTIN, Claude. Por uma geografia do poder. São Paulo: Ática, 1993. 269 p.

RIO GRANDE DO SUL. Convênio que entre si celebram, de um lado, o Estado do Rio Grande do Sul, com interveniência da Secretaria de Ciência e Tecnologia e da Secretaria da Coordenação e Planejamento e, de outro lado, a Fundação Universidade de Caxias do Sul, visando à conjugação de esforços e recursos 
para continuidade de programas do Pólo de Modernização Industrial da Região da Serra. Porto Alegre: Secretaria de Ciência e Tecnologia, 28 nov. 1995. 6 p.

RIO GRANDE DO SUL. Termo de Cooperação Interinstitucional que entre si celebram a Secretaria de Ciência e Tecnologia do Rio Grande do Sul, a Associação Riograndense de Empreendimentos de Assistência Técnica e Extensão Rural - Emater/RS, juntamente com a Associação Sulina de Crédito e Assistência Rural - Ascar, o Município de Caxias do Sul-Rs, a Universidade de Caxias do Sul, a Fundação Estadual de Pesquisa Agropecuária - Fepagro, visando ao funcionamento de um Centro de Treinamento para Agricultores em Fazenda Souza, Município de Caxias do Sul. Porto Alegre: Secretaria de Ciência e Tecnologia, 1998. 6 p.

ROSECRANCE, Richar. La expansión del Estado comercial. Comércio y conquista en el mundo moderno. Madrid: Alianza Editorial, 1986. 261 p.

RÜCKERT, Aldomar A. Reforma do Estado e tendências de reestruturação territorial. Cenários contemporâneos no Rio Grande do Sul. 2001. 662 f. Tese (Doutorado) - FFLCH, Programa de Pós-Graduação em Geografia Humana, Universidade de São Paulo. São Paulo.

SANTOS, Milton. Espaço e método. São Paulo: Nobel, 1985. 88 p.

SCHNEIDER, Hermes. Pólos de modernização tecnológica: o caso do Programa Regional de Cooperação Científica e Tecnológica da região Noroeste do Estado do Rio Grande do Sul. 1997. 158 f. Dissertação (Mestrado em Administração), Programa de Pós-Graduação em Administração, Universidade Federal do Rio Grande do Sul, Porto Alegre.

UNIVERSIDADE DE CAXIAS DO SUL. A regionalização da Universidade: conceitos e perspectivas. Caxias do Sul, 1992. 30 p.

UNIVERSIDADE DE CAXIAS DO SUL. Protocolo de Intenções que entre si celebram a Fundação Universidade de Caxias do Sul (FUCS), o Município de Caxias do Sul e a Câmara de Indústria, Comércio e Serviços de Caxias do Sul (CIC), visando a constituição de uma Incubadora de Empresas de Base Tecnológica. Caxias do Sul, 1996. 
UNIVERSIDADE DE CAXIAS DO SUL. Pólo oleoquímico de plantas aromáticas e medicinais do Rio Grande do Sul. Caxias do Sul, 1999. 19 p.

UNICAMP. Termo aditivo no 1 que entre si celebram a Universidade de Caxias do Sul e a Universidade Estadual de Campinas com a interveniência administrativa da Fundação de Desenvolvimento da Unicamp. Campinas, 25 jun. 1997. 10 p.

WILSON, Patricia A. Reconociendo la localidad en el desarrollo económico local. Revista Interamericana de Planificación, v. 28, no 110, abr./jun. 1995. p. 9-15.

Recebido: 05/01/2004

Revisado: 20/01/2004

Aceite final: 13/03/2004

\section{Resumo}

O artigo analisa políticas territoriais, especificamente aquelas direcionadas para o desenvolvimento endógeno com base local. O Programa dos Pólos de Modernização Tecnológica da Serra da Secretaria de Ciência e Tecnologia do Estado do Rio Grande do Sul tem sido implantado por Universidades comunitárias, principalmente, na década de 90. As ações dos atores coletivos civis, no sentido de implantação de políticas de inovação no Pólo de Modernização Tecnológica da Serra na Universidade de Caxias do Sul, região de planejamento do Conselho Regional de Desenvolvimento da Serra são analisadas especificamente nos municípios de Caxias do Sul e Campestre da Serra.

Palavras-chave: políticas territoriais, desenvolvimento endógeno com base local, Pólo de Modernização Tecnológica da Serra, Caxias do Sul (RS), Campestre da Serra (RS). 